\title{
The Effects of EGR on the Performance and Exhaust Emissions of a Diesel Engine Operated on Diesel Oil and Soybean Oil Methyl Ester (SOME)
}

\author{
S. Ghosh ${ }^{1}$, D. Dutta ${ }^{2}$ \\ ${ }^{I}$ Asst Prof., Camellia School of Engineering \& Technology, Barasat, Kolkata - 700124, W.B., India. \\ ${ }^{2}$ Asst Prof., Camellia School of Engineering \& Technology, Barasat, Kolkata - 700124, W.B., India.
}

\begin{abstract}
Bio-diesel is an attractive alternative fuel which is renewable, non-toxic, and offer potential reduction of carbon monoxide and hydrocarbon emission due to higher oxygen content. Biodiesel can be easily blended with petroleum diesel to create biodiesel blends, and is free of sulphur. Emission control has become one of the most important challenges in diesel engine. The aim of the present work is to reduce NOx emissions of a diesel engine. Exhaust gas recirculation (EGR) is one of the most effective ways for reducing NOx emissions in diesel engine. A single cylinder four stroke direct injection water cooled diesel engine is operated with soybean oil methyl ester (SOME) and neat diesel and EGR which replaces a fraction of incoming air during suction. Three observations are made for performance and exhaust gas emission analysis using $0 \%$ EGR, 5\% EGR and 10\% EGR. The rotational speed of the engine is kept as constant at $1500 \mathrm{rpm}$. The performance of the engine in terms of specific fuel consumption, and brake thermal efficiency and emission characteristics such as oxides of nitrogen, hydrocarbon and smoke density is compared. The observations revel that, biodiesel with EGR can be used to reduce NOx and smoke intensity simultaneously.
\end{abstract}

Keywords:- Emission, Exhaust gas Recirculation, Soybean oil methyl ester, Diesel engine, Bio-diesel.

\section{INTRODUCTION}

Economic growth of a country is very much dependent on the long term availability of energy. The sources of energy should be safe and environment friendly. Diesel engine is preferred prime movers for power generation due to its excellent drivability and higher thermal efficiency. Despite their advantages they produce higher levels of NOx and smoke emissions which have significant effect on human, animal, plant, and environmental health and welfare. In order to meet the emission norms and also the depletion of petro diesel oil reserves lead to the research for alternative fuels for diesel engines. Biodiesel from vegetable oils are alternative to diesel fuel for diesel engines. The use of biodiesel in diesel engines does not require any engine modification. An important property of biodiesel is its oxygen content which is usually not contained in diesel fuel. Biodiesel gives considerably lower emissions of PM, carbon monoxide (CO) and hydrocarbon (HC) without any fuel consumption or engine performance penalties. Exhaust gas recirculation (EGR) can be used with biodiesel in the diesel engines. EGR is an effective technique of reducing NOx emissions from the diesel engine exhaust.

Ladommatos et al. (1998) tested the effect of exhaust gas recirculation on diesel engine emissions. They noticed a large reduction in NOx emissions at the expense of higher particulate and un-burnt hydrocarbon emissions. [1]. D.Agarwal (2006) suggested that controlling the NOx emissions primarily requires reduction of in-cylinder temperatures. [2].

Y. Yoshimoto (1999) reported that the application of EGR results in higher fuel consumption and emission penalties, also EGR increases HC, CO, and PM emissions along with slightly higher specific fuel consumption. [3]. Yokomura et al. (1994) have suggested that exhaust gas recirculation is one of the most effective ways for nitrogen oxides (NOx) reduction process. [4]. Zheng, G. T. Reader (2004) et al. have studied the effect of EGR on NOx emission and reported that the EGR rates are sufficient for high load, also as the load increases; diesel engines tend to generate more smoke because of reduced oxygen. Therefore, EGR, although effective to reduce NOx, further increases the smoke and PM emissions. [5].

A.K. Agrawal et al. (2004) reported that in diesel engines NOx formation is very much depended upon temperature. To reduce NOx emission in the exhaust of a diesel engine, it is necessary to keep combustion temperature under control. [6]. Santoh et al. (1997) done an experiment on a naturally aspirated single cylinder DI diesel engine with various combinations of EGR, fuel injection pressures, injection timing and intake gas temperatures affect exhaust emissions and they found that NOx reduction ratio has a strong correlation with oxygen concentration regardless of injection pressure or timing. EGR lowers the average combustion temperature and reduces the oxygen intake gases that adversely affect the smoke emission and soot formation. 
They also suggested that for a given level of oxygen concentration the cooled EGR reduces more NOx with less EGR rates than does at hot EGR [7]. Abu-Jrai et al, (2007) have analyzed the effect of exhaust gas recirculation (EGR) on pollutant emission in diesel engine. [8].

Saravanan et al. (2008) performed a series of test on a single cylinder water cooled DI diesel engine with hydrogen was used as dual fuel mode with EGR technique. They reported increase in brake thermal efficiency and lowered smoke level, particulate and NOx emissions due to absence of carbon in hydrogen fuel. [9]. Hountalas et al. (2008) have presented 3D-multi dimensional model to examine the effect of EGR temperature on a turbocharged DI diesel engine with three different engine speeds. They reported that high EGR temperature affects the engine brake thermal efficiency, peak combustion pressure, air fuel ratio and also soot emissions, and the combined effect of increased temperature and decreased $\mathrm{O} 2$ concentration resulted low NOx emissions. Also they suggested that EGR cooling is necessary to retain the low NOx emissions and prevent rising of soot emissions without affecting the engine efficiency at high EGR rates. [10].

Abd-Alla et al. (2001) have done experiments on a dual fuel (gaseous fuel- methane with diesel as pilot fuel) mode direct injection diesel engine to study the effect of inlet air temperature by the way of mixing of hot EGR and addition of diluents gas such as $\mathrm{CO} 2$ and N2 They observed that the addition of CO2 gas in the intake charge increased un-burnt hydrocarbon emission (UBHC) but moderate reduction of NOx emission. By increasing the intake charge temperature NOx emission was increase with decrease in UBHC. The brake thermal efficiency and power output increased due to reduced ignition delay. Also they suggested that the performance was improved at low load condition when the intake air temperature was increased. [11].

The main objective of the present work is to investigate the effect of different exhaust gas re-circulation rate on the engine performance and exhaust emission and compared when operated the engine with soybean oil methyl ester (SOME) and diesel fuel.

\section{EXHAUST GAS RE-CIRCULATION SYSTEM}

In exhaust gas recirculation process, a fraction of the engine out exhaust gas is re-circulated to the engine. Oxides of nitrogen are formed when the temperature inside the combustion chamber exceeds the critical temperature so that the molecules of nitrogen and oxygen combine [4]. Inter-mixing the incoming air with recirculated exhaust gas basically cuts off some percentage of the oxygen going into the combustion chamber and lowers the adiabatic flame temperature. The exhaust gas increases the specific heat of the mixture and lowers the peak combustion temperature. NOx formation progresses faster at higher temperatures. EGR serves to limit the formation of NOx. There is no doubt that EGR is very effective in reducing oxides of nitrogen, but it also has adverse effects on the engine efficiency. As it contains a lot of particulate matter, it may also contaminate the lubricating oil and can also foul the intake manifold [4].

\section{EXPERIMENTAL SETUP}

An experimental investigation was carried out to investigate the influence of exhaust gas recirculation on the performance and exhaust emission of a diesel engine. The engine used for the investigation was computerized single-cylinder, four-stroke, and water cooled diesel engine with eddy current dynamometer. The technical specifications of the engine are given in Table I, and the schematic of the experimental setup is shown in Figure 1. The power output of the engine was measured by an electrical dynamometer. AVL gas analyzer was used for the measurement of amounts of exhaust emissions. For smoke opacity measurement AVL smoke meter was used. Rota meters were used to measure the volume flow rates of inlet charge as well as exhaust gas to be re-circulated. Digital control panel was used to collect data such as torque, water flow of engine etc. A known quantity of exhaust gas with air was re-circulated into the combustion chamber and was performed with manually controlled EGR valve. The exhaust gas that came out from the engine was at very high pressure and temperature. The measurements were taken after steady state of the engine for each set of readings.

Table1. Engine specifications

\begin{tabular}{|l|l|}
\hline Type of engine & $\begin{array}{l}\text { Water cooled Four } \\
\text { stroke }\end{array}$ \\
\hline Number of cylinder & one \\
\hline Bore & $87.4 \mathrm{~mm}$ \\
\hline Stroke & $110 \mathrm{~mm}$ \\
\hline Compression ratio & $17.5: 1$ \\
\hline Rated speed & $1500 \mathrm{rpm}$ \\
\hline Maximum Power & $5.2 \mathrm{~kW}(7 \mathrm{hp})$ \\
\hline Maximum torque & $30 \mathrm{~N}-\mathrm{m}$ \\
\hline
\end{tabular}


The Effects of EGR on the Performance and Exhaust Emissions...

Table-2: Properties of Test fuels

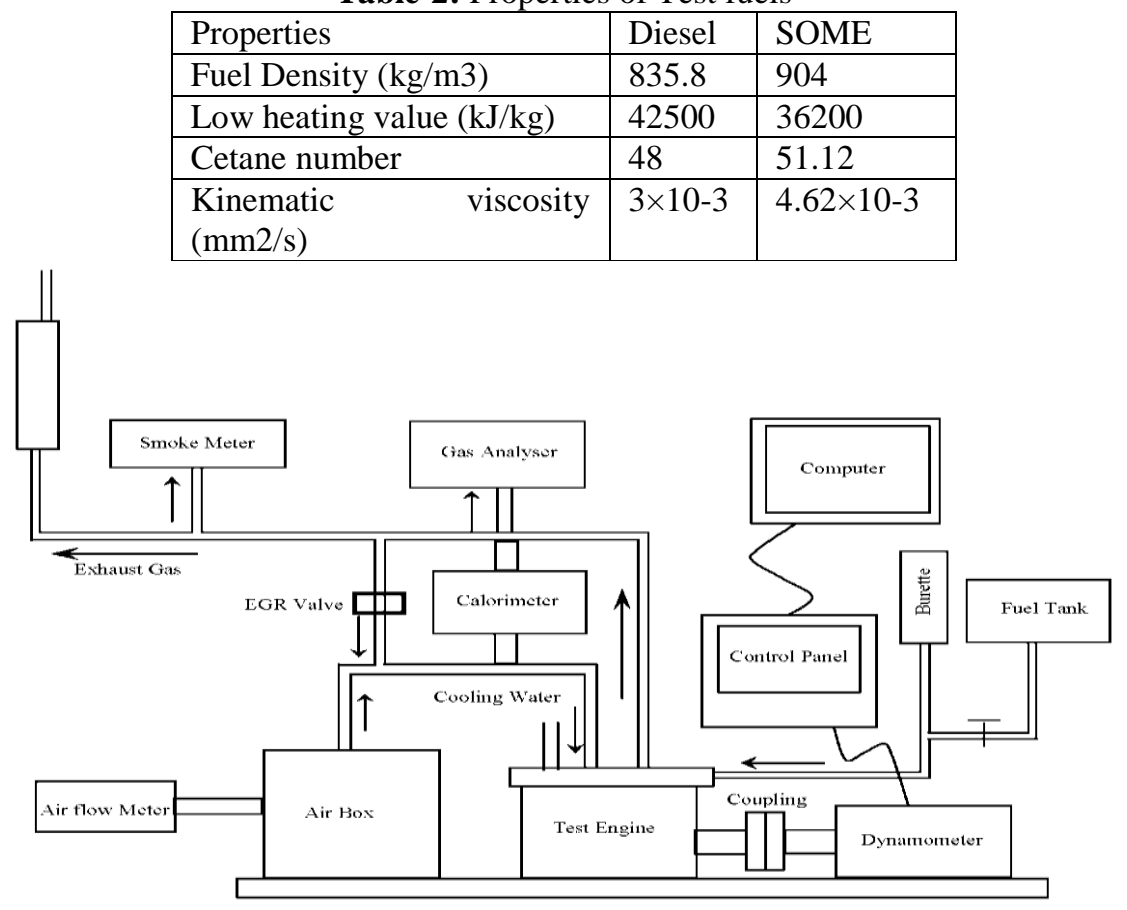

Fig.1: Schematic of Experimental Setup

IV. CALCULATION OF THE EGR RATE

When the impact of EGR on the emissions is assessed, it is essential to know the EGR ratio

Mass of EGR

$\% \mathrm{EGR}=$ $\times 100$

Mass of total intake mixture into the cylinder

Another way to define the EGR ratio is by the use of CO2 concentration (Baert et al 1999). [12].

[CO2] intake - [CO2] ambient

EGR ratio $=$------ $[\mathrm{CO} 2]$ exhaust $-[\mathrm{CO} 2]$ ambient

\section{RESULTS AND DISCUSSIONS}

The experiment was carried out in a four stroke single cylinder, water cooled diesel engine using diesel and soybean oil methyl ester (SOME) at $1500 \mathrm{rpm}$ and different EGR rates to study the effect of EGR on the performance of the engine like brake thermal efficiency and specific fuel consumption and emission characteristics like HC emission smoke density and NOx concentration in the tail pipe emissions. Higher amount of smoke emission is observed in the exhaust when the engine is operated with EGR compared to without EGR in both cases. Smoke emissions increases with increasing engine load and EGR rates.EGR reduces availability of oxygen for combustion of fuel, which results in relatively incomplete combustion and increased formation of PM and reducing NOx emissions from diesel engine. Using biodiesel in diesel engine, smoke is decreased with increase in NOx. Thus, biodiesel with EGR can be used to reduce NOx and smoke intensity simultaneously.

\section{Brake thermal efficiency}

Figure 2(a) and 2(b) shows the variations of brake thermal efficiency with brake power of diesel and soybean oil methyl ester (SOME) respectively with and without EGR at constant speed of the engine. It is observed from the figures that the brake thermal efficiencies are increased with increase in load with or without EGR at lower load. This is due to re-burning of hydrocarbons that enter in to the combustion chamber during suction with the re-circulated exhaust gases. Brake thermal efficiency of diesel fuel is higher than SOME at all loading conditions with and without EGR operations due to higher heating value of the diesel fuel. At full load operation the brake thermal efficiency marginally decreases in both cases with the increase of the EGR rate. 


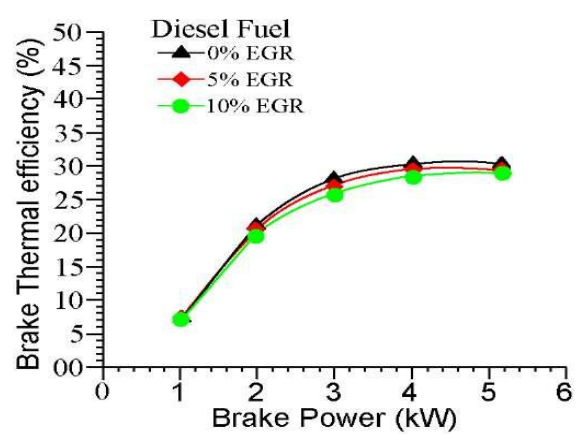

(a)

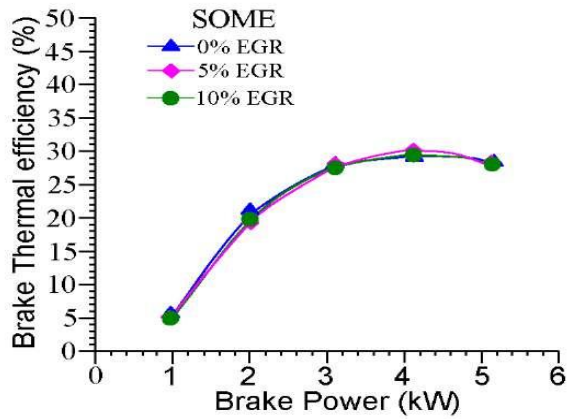

(b)

Fig.2: Variation of brake thermal efficiency with brake power for diesel and SOME.

\section{Specific fuel consumption}

Figure 3(a) and 3(b) shows the variations of SFC with brake power for diesel and biodiesel (SOME) respectively with and without EGR at constant speed of the engine. The specific fuel consumptions are lower for diesel at all loading conditions when operated with EGR and without EGR when compared to SOME. So, for SOME more mixtures are required for constant power output. However, at higher loads of the engine, SFC with $10 \%$ EGR is almost same to that of without EGR for diesel fuel but $7.4 \%$ higher at full load operation for SOME with $10 \%$ EGR.

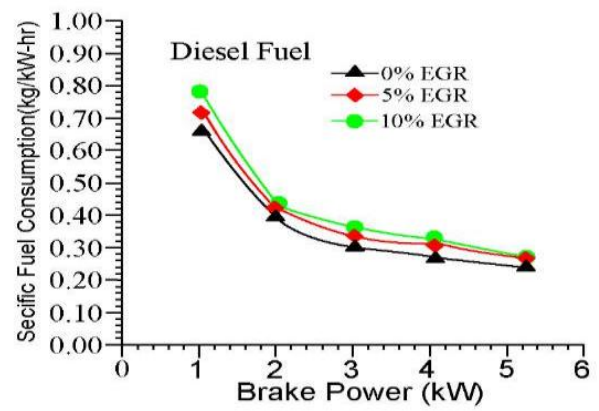

(a)

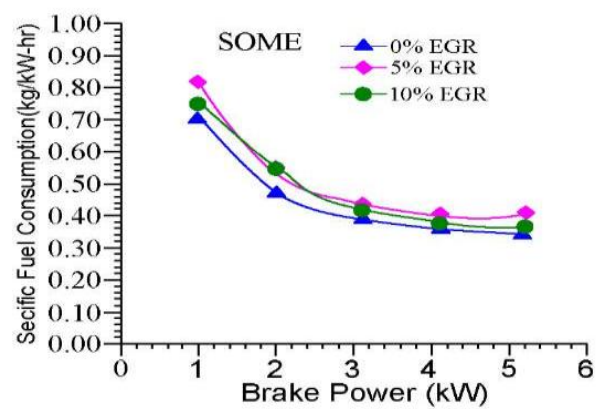

(b)

Fig.3: Variation of Specific Fuel Consumption with Brake Power

\section{Oxides of nitrogen emission (NOx)}

Figure 4 (a) and 4(b) shows the variations of NOx emissions with brake power of diesel and soybean oil methyl ester (SOME) respectively with and without EGR at constant speed of the engine. It is observed from the figure that the bio-diesel emits higher NOx than diesel fuel at all loading conditions due to higher oxygen content of bio-diesel provide high local temperature and complete combustion of the bio-diesel. The emission of NOx tends to decrease significantly with the increase of EGR rate for all loading conditions for both the fuels due to reduction of oxygen concentration for the presence of inert gases such as $\mathrm{CO} 2$ and $\mathrm{H} 2 \mathrm{O}$ in the cylinder that decreased the flame temperatures in the combustion chamber. At full load condition NOx emission for diesel and SOME are respectively 798ppm and $880 \mathrm{ppm}$ at constant speed of the engine without EGR. From the figure it is observed that maximum NOx reduction occurs with 10\% EGR. At full load condition reduction of NOx for SOME and diesel was respectively 160ppm and 130ppm with 10\% EGR.

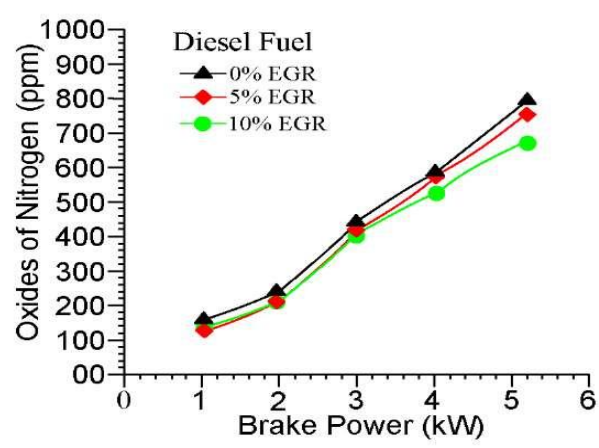

(a)

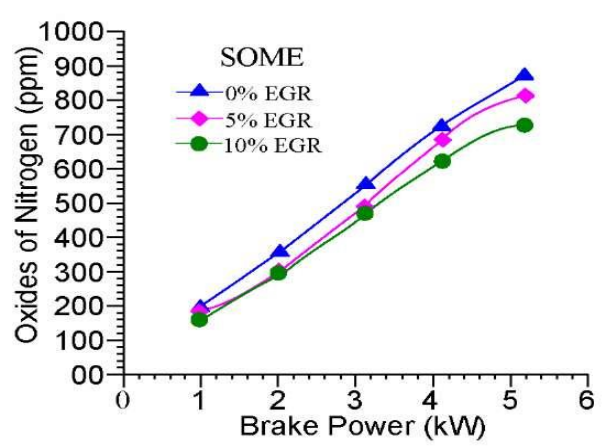

(b)

Fig.4: Variation of Oxides of Nitrogen with Brake Power 


\section{Smoke density (HSU)}

Figure 5(a) and 5(b) shows the variations of smoke emissions with brake power of diesel and soybean oil methyl ester (SOME) respectively with and without EGR at constant speed of the engine. Higher amount of smoke emission is observed in the exhaust when the engine is operated with EGR compared to without EGR in both cases. Smoke emissions increases with increasing engine load and EGR rates.EGR reduces availability of oxygen for combustion of fuel, which results in relatively incomplete combustion and increased formation of PM and reducing NOx emissions from diesel engine. Soybean oil methyl ester (SOME) showed 5.5\% lower smoke compared to diesel oil at full load condition when operated without EGR due to the oxygen content of the bio-fuel molecules resulting more complete combustion of the bio-diesel. At full load condition almost same smoke emission is observed for both the fuels with EGR.

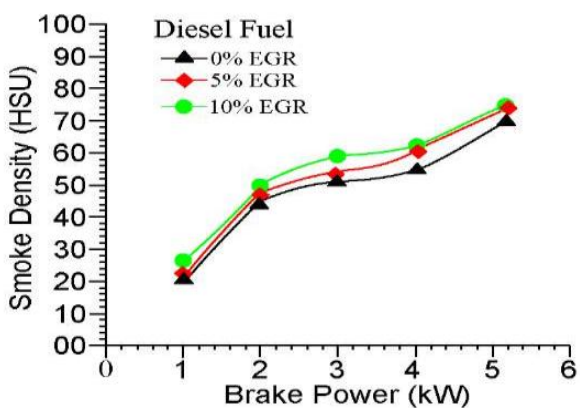

(a)

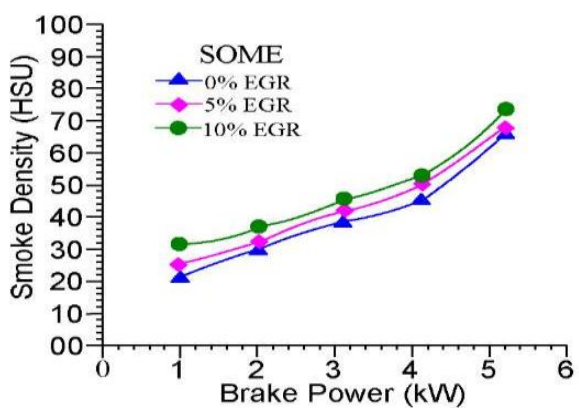

(b)

Fig.5: Variation of Smoke Density with Brake Power

\section{Hydrocarbon emission (HC)}

Figure 6(a) and (b) shows the variations of hydrocarbon (HC) emissions with brake power of diesel and soybean oil methyl ester (SOME) respectively with and without EGR at constant speed of the engine. From the figure it is observed that hydrocarbon emission increases with the increase with load in the engine due to insufficient amount of oxygen in the combustion chamber resulting incomplete combustion. Due to presence of molecules of oxygen in soybean oil methyl ester emits lower HC than diesel fuel. At full load condition SOME emits $12 \%$ and $7.5 \%$ lower HC than diesel when operated without EGR and with10\% EGR.

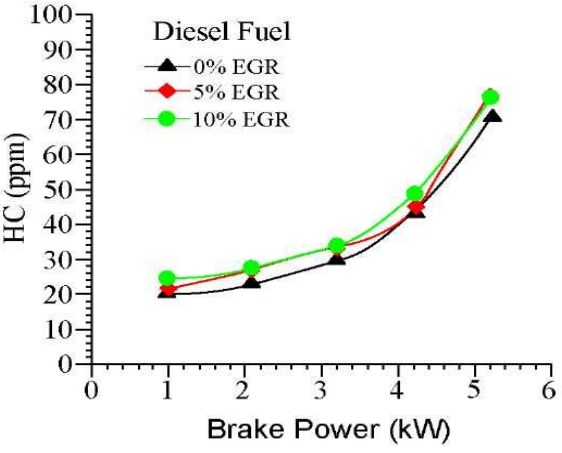

(a)

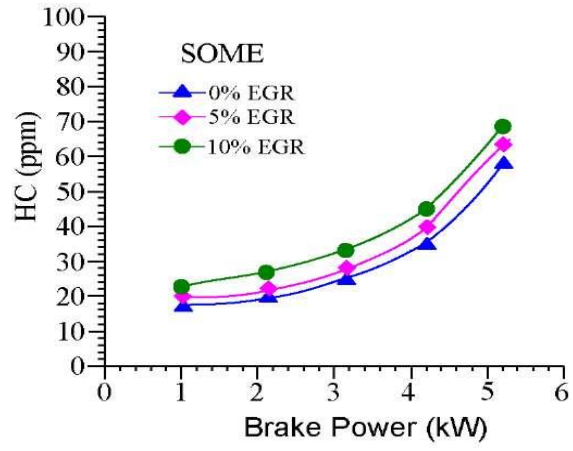

(b)

Fig.6: Variation of Hydrocarbon Emission with Brake Power

\section{CONCLUSION}

An experimental investigation was carried out on a single cylinder four stroke, water cooled diesel engine operated on diesel fuel and soybean oil methyl ester (SOME) with exhaust gas recirculation. The effect of EGR on the performance and exhaust emissions of the diesel engine were analyzed. The results of this study may be concluded as follows:

1. When the engine was operated with SOME, the brake thermal efficiency decreases due to the lower calorific value of biodiesel compared to net diesel fuel. The brake thermal efficiency increases at low EGR rates for both the fuels. However, increasing EGR flow rates to high levels resulted in decrease in brake thermal efficiency for both net diesel fuel and SOME.

2. It is observed from the figure that the bio-diesel emits higher NOx than diesel fuel at all loading conditions. The NOx emissions were decreased with increase in EGR flow rate for both net diesel fuel and SOME.

3. The emissions of smoke and HC were found to be lower with SOME.. However, with the increase of EGR flow rates resulted in considerable rise in smoke and $\mathrm{HC}$ emissions for both net diesel fuel and SOME. 
4. The specific fuel consumption for SOME was slightly higher than diesel fuel at all loading conditions when operated with and without EGR.

\section{REFERENCES}

1) Ladommatos.N, S.M. Abdelhalim, H. Zhao and Z. Hu., The effects of carbon dioxide in exhaust gas recirculation on diesel engine emissions, Journal of Automobile Engineering, 212, (1998) 25-42.

2) Agarwal.D, S. Sinha, A. K. Agarwal, Experimental investigation of control of NOx emissions in biodiesel - fuelled compression ignition engine, Renewable Energy, 31, (2006), 2356-2369.

3) Yoshimoto.Y, M.Onodera, H.Iamaki, Reduction of NOx and smoke and BSFC in a diesel Engine Fueled by Biodiesel Emulsion with Used Frying Oil, SAE Transaction, 1999-01-3598 , (1999). 19131929.

4) Yokomura.H, S. Kohketsu, K. Mori., EGR system in a turbocharged and intercooled heavy-duty diesel engine; Expansion of EGR area with venturi system, Technical review, Mitsubishi Motors Corporation, 2003.

5) Zheng.M, G. T. Reader, J. G. Hawley, Diesel engines exhaust gas recirculation-a review on advanced and novel concepts. Energy Conversion Management, 45, (2004), 883-900.

6) Agrawal. A. K, Singh. S. Sinha. S. Shukla. M. K., Effect of EGR on the exhaust gas temperature and exhaust opacity in compression ignition engines. Sadhana, 29(3), (2004), 275-284.

7) Santoh.K, L. Zhang, H. Hatanaka, T. Takatsuki, K. Yokoto, Relationship between NOx and SM emissions from DI diesel engine with EGR. Society of Automotive engineers of Japan, 18, (1997), 369375.

8) Abu-Jrai, A. Tsolakis, A.Megaritis., The influence of $\mathrm{H} 2$ and $\mathrm{CO}$ on diesel engine combustion characteristic, exhaust gas emissions, and after treatment selective catalytic NOx reduction. International Journal of Hydrogen Energy, 32, (2007), 3565-3571.

9) Saravanan.N, G. Nagarajan, K.M. Kalaiselvan, C. Dhanasekaran, An experimental investigation on hydrogen as a dual fuel for diesel engine system with exhaust gas recirculation technique. Renewable Energy, 33, (2008), 422-427.

10) Hountalas.D.T G. C. Mavropoulos, K. B. Binder, Effect of exhaust gas recirculation (EGR) temperature for various EGR rates on heavy duty DI diesel performance and emissions. Energy, 33, (2008), 272-283.

11) Abd-Alla,G.H H. A. Soliman, O. A. Badr, M.F. Rabbo, Effects of diluents and intake air temperature in exhaust gas recirculation of an indirect injection dual fuel engine. Energy Conversion Management, 42, (2001), 1033-1045.

12) Baert, R., Beckman, D., and Veen, A., Efficient EGR Technology for Future HD Diesel Engine Emission Targets, SAE Technical Paper, 1999-01-0837, 1999. 